\title{
Rare Cause of Left Upper Abdominal Pain
}

\author{
Bibiana Aiyegbeni, Saleem Jonnalagadda, Lee Creedon, Aija Teibe
}

Grantham and District Hospital, Grantham, United Kingdom

Received July 4, 2020; Accepted April 30, 2021.

Key words: Jejunal diverticulitis - Diverticular disease - Acute abdomen Duodenal diverticulum

Abstract: Inflamed diverticular disease of the small bowel is an uncommon cause of acute abdominal pain. Despite its low prevalence rate $(0.3-2 \%)$, it is associated with a high mortality rate between 20-25\% (Fisher and Fortin, 1977; FerreiraAparicio et al., 2012). This is due to complications including perforation, bleeding, and obstruction. This case report presents the diagnosis and management of Mr. X, a 70 -year-old male with jejunal diverticulitis and a duodenal diverticulum. Mr. $\mathrm{X}$ has a background of type 2 diabetes mellitus and sigmoid diverticulosis, he presented with a three-day history of left upper quadrant pain radiating to the left iliac fossa. He was haemodynamically stable despite his elevated inflammatory markers (C-reactive protein $161 \mathrm{mg} / \mathrm{I}$ and neutrophils $13.3 \times 10^{9} / \mathrm{I}$ ) and computerised tomography (CT) of the abdomen and pelvis showing jejunal diverticulitis and a duodenal diverticulum. Mr. X was successfully treated with intravenous antibiotics and analgesia and a follow up CT scan showed that the jejunal diverticulitis had resolved. Previous operative management of the discussed pathology has been reported, the current report is novel as the diagnosis was made early and the case managed conservatively.

Mailing Address: Dr. Bibiana Aiyegbeni, MBBS., Bsc., 68 Kent Close, Mitcham, CR4 1XP, United Kingdom; e-mail: bibiana.aiyegbeni@yahoo.co.uk 


\section{Introduction}

Small bowel diverticular disease excluding, Meckel's diverticulitis, is an uncommon cause of acute abdominal pain. It occurs in approximately $0.3-1.3 \%$ of post-mortem cases and $0.5-1.9 \%$ of contrast media study cases (Fisher and Fortin, 1977). Whereas, more common small bowel emergencies are bowel obstruction, small bowel inflammation (especially terminal ileum) and/or perforation in patients with Crohn's disease (Vallicelli et al., 2011). In these cases, if the affected small bowel is unsalvageable then resection is the definitive surgical approach. Moreover, multiple small bowel diverticuli have been linked with various clinical conditions including Fabry's disease, Marfan's and Ehlers Danlos syndrome (Cunliffe and Anderson, 1967; Friedman et al., 1984; McLean et al., 1985; Shapira et al., 1992; Yağmur et al., 2004; Aksoy et al., 2005).

The jejunum is the least common site of small bowel diverticula with an incidence of less than $0.5 \%$ in upper $\mathrm{Gl}$ (gastrointestinal) radiographs and $0.3-1.3 \%$ autopsy incidences (Chow et al., 1997). Duodenal diverticula are approximately five times more common than jejunoileal diverticula. Small bowel diverticula are often symptomatic, with approximately $10 \%$ of patients presenting with acute clinical symptoms (Cunningham et al., 2006).

The prevalence of jejunal diverticular disease increases with age, mostly occurring in older males between the age of 60-80 years old (Akhrass et al., 1997). Complicated small bowel diverticular disease has a mortality rate as high as $24 \%$ with serious complications including perforation, bleeding, abscess formation and obstruction (Ferreira-Aparicio et al., 2012). Therefore, it is important for clinicians to consider small bowel diverticula in patients who present with symptoms such as abdominal pain, nausea and fever. There is little research on the presentation and management of patients with small bowel diverticulitis. Nonetheless, previous case reports have shown that both medical and surgical intervention may be required to treat the complications (Kouraklis et al., 2001).

This report presents a case of a male patient with jejunal diverticulitis and a duodenal diverticulum, with discussion of literature on this rare condition.

\section{Case report}

A 70-year-old male with a history of sigmoid diverticulosis and type 2 diabetes mellitus presented to the emergency department with a three-day history of progressive, constant left upper quadrant pain. The pain was dull in nature and radiated to the left iliac fossa. Pain severity at its worst was $8 / 10$, worse with movement and relieved by lying flat. It was associated with reduced appetite and fever but no nausea. Physical examination showed marked left lumbar and iliac fossa tenderness with no peritonism. There was a suspected mass in the left lumbar region.

The patient's white cell count was $14.8 \times 10^{9} / \mathrm{I}\left(4.3-11.2 \times 10^{9} / \mathrm{I}\right)$, C-reactive protein $161 \mathrm{mg} / \mathrm{I}(0-5 \mathrm{mg} / \mathrm{I})$, neutrophils $13.26 \times 10^{9} / \mathrm{I}\left(2.1-7.4 \times 10^{9} / \mathrm{I}\right)$, lymphocytes 
108) Prague Medical Report / Vol. 122 (2021) No. 2, p. 106-111

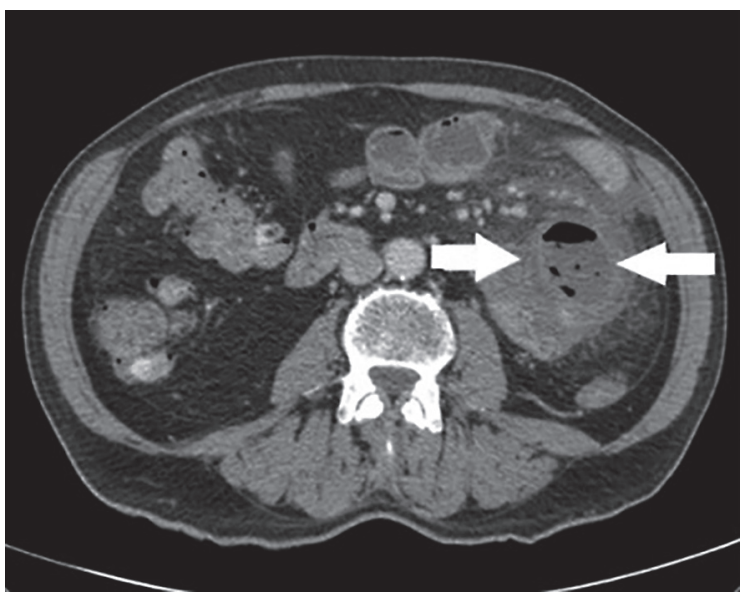

Figure 1 - Computed tomography scan of the abdomen and pelvis for the patient. Jejunal diverticulitis is shown in white arrows.

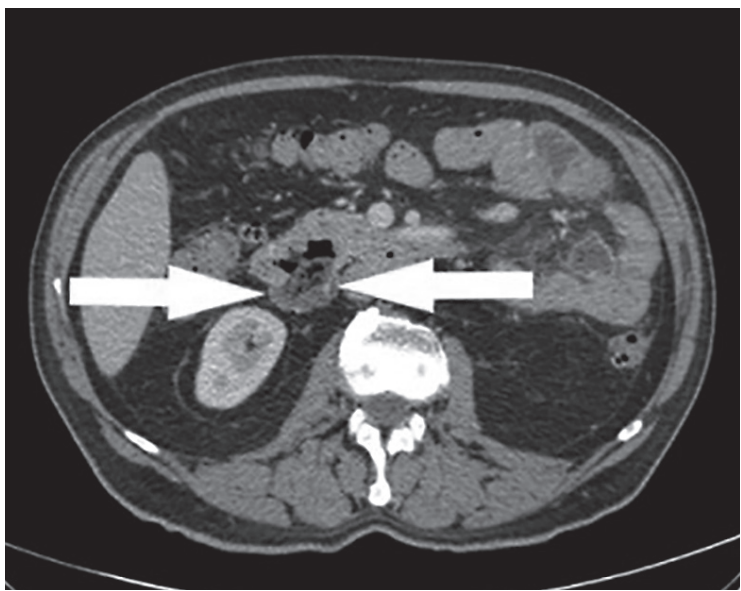

Figure 2 - Another slice of the same computed tomography abdomen and pelvis scan as in Figure 1 for the patient. In white arrows, the duodenal diverticulum is shown.

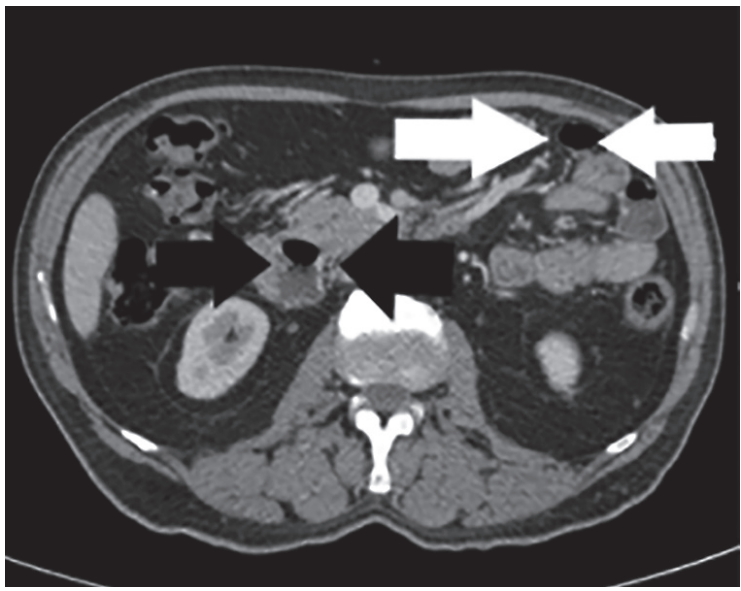

Figure 3 - Computed tomography abdomen and pelvis scan is being shown post treatment of the jejunal diverticulitis shown in the white arrow. The black arrow shows the duodenal diverticulum.

Aiyegbeni B.; Jonnalagadda S.; Creedon L.; Teibe A. 
$0.65 \times 10^{9} / \mathrm{I}\left(1.0-3.6 \times 10^{9} / \mathrm{I}\right)$, lactate $<2 \mathrm{mmol} / \mathrm{I}$ and all other laboratory data was unremarkable. An abdominal and pelvis computed tomography (CT) scan with contrast showed large inflamed jejunal diverticulum with surrounding inflammatory mass and no obvious features of bowel ischaemia (Figure 1). Diverticular disease of the duodenum and the left colon was also noted (Figure 2).

The patient was treated with intravenous co-amoxiclav and metronidazole and remained nil by mouth. He was discharged home on day 5 with oral co-amoxiclav for an additional seven days and followed-up with repeat outpatient CT in six weeks' time.

Repeat imaging showed that the inflammation in the left flank had resolved without complication (Figure 3) and the patient was discharged from the general surgery clinic.

\section{Discussion}

We present a case of a 70-year-old man with a history of sigmoid diverticular disease who presented with acute left sided abdominal pain and was found to have jejunal diverticulitis.

Compared to large bowel diverticular disease, small bowel diverticular disease is uncommon. The duodenum is more common than the jejunal-ileal sites for small bowel diverticulosis except for Meckel's diverticulum (Hobson and Roberts, 2004). One theory of the pathophysiology of small bowel diverticulosis is that there are abnormalities of intestinal peristalsis and high intraluminal pressure, so the diverticulum exists at the site where mesenteric vessels enter the muscular layer of the small intestine (Hobson and Roberts, 2004). There is little information on the incidence of duodenal, jejunal and ileal diverticular simultaneously. Krishnamurthy et al. (1983) showed in their study of 10 patients that $40 \%(n=4)$ had simultaneous duodenal, jejunal and ileal diverticulae; however, this was a small sampled study, so it is difficult to make generalisations from this study.

Diverticula can also be classified as either congenital or acquired. Except for Meckel's diverticulum, small bowel diverticula tend to be acquired rather than congenital (Albert et al., 2009). Diverticula can also be classed as either true or pseudodiverticula. A true diverticulum such as in Meckel's diverticulum (on the antimesenteric border of ileum) involves all layers of the bowel whereas pseudodiverticula consists of the uncus of the mucosa and the submucosa (Albert et al., 2009). Jejunal diverticulum tend to be pseudodiverticula (Chow et al., 1997; Mantas et al., 2011).

On radiological findings, inflamed diverticula tend to appear as non-specific changes suggestive of inflammation. This may include an inflammatory mass, bowel wall thickening of an involved segment, surrounding fat stranding and fluid collections (Coulier et al., 2007; Kirbas et al., 2007).

Patients can present with complicated diverticulitis including abscess formation, perforation and ischaemia. These complications generally require surgical 
intervention. The case we present was diagnosed early without complication and therefore antibiotic treatment alone was effective. Previous reports describe failed initial medical management where patients went on to suffer complications including diverticular bleeding and perforation (Kumar, 2017; Prough et al., 2019). In Prough et al. (2019) case report, the patient was suspected of having acute perforated jejunal diverticulitis, but this was disproved at operation. Nonetheless, the affected segment was resected.

\section{Conclusion}

It is important to consider a differential diagnosis of small bowel diverticulitis in patients with acute abdominal pain. Early radiological investigation is important and surgical intervention should be considered if medical management is insufficient or complications occur. Future studies could investigate the number of cases of small bowel diverticulitis which are managed medically vs surgical management, however this may be difficult as this is not a common condition.

\section{References}

Akhrass, R., Yaffe, M. B., Fischer, C., Ponsky, J., Shuck, J. M. (1997) Small bowel diverticulosis: perceptions and reality. J. Am. Coll. Surg. 184(4), 383-388.

Aksoy, F., Demirel, G., Bilgiç, T., Güngör, I. G., Ozcelik, A. (2005) A previously diagnosed mitochondrial neurogastrointestinal encephalomyopathy patient presenting with perforated ileal diverticulitis. Turk. J. Gastroenterol. 16(4), 228-231.

Albert, J. G., Lübbert, G., Surow, A., Zeuzem, S. (2009) Small bowel diverticula - unknown disease. Z. Gastroenterol. 47, 674-681. (in German)

Chow, D. C., Babain, M., Taubin, H. L. (1997) Jejunoileal diverticula. Gastroenterologist 5, 78-84.

Coulier, B., Maldague, P., Bourgeois, A., Broze, B. (2007) Diverticulitis of the small bowel: CT diagnosis. Abdom. Imaging 32, 228-233.

Cunliffe, W. J., Anderson, J. (1967) Case of Cronkhite-Canada syndrome with associated jejunal diverticulosis. Br. Med. J. 4(5579), 601-602.

Cunningham, S. C., Gannon, C. J., Napolitano, L. M. (2006) Small bowel diverticulosis. Am. J. Surg. 190, 37-38.

Ferreira-Aparicio, F. E., Gutiérrez-Vega, R., Gálvez-Molina, Y., Ontiveros-Nevares, P., Athie-Gútierrez, C., Montalvo-Javé, E. E. (2012) Diverticular disease of the small bowel. Case Rep. Gastroenterol. 6, 668-676.

Fisher, J. K., Fortin, D. (1977) Partial small bowel obstruction secondary to ileal diverticulitis. Radiology 122, 321-322.

Friedman, L. S., Kirkham, S. E., Thistlethwaite, J. R., Platika, D., Kolodny, E. H., Schuffler, M. D. (1984) Jejunal diverticulosis with perforation as a complication of Fabry's disease. Gastroenterology 86(3), 558-563.

Hobson, K. G., Roberts, P. L. (2004) Etiology and pathophysiology of diverticular disease. Clin. Colon Rectal Surg. 17(3), 147-153.

Kirbas, I., Yildirim, E., Harman, A., Basaran, O. (2007) Perforated ileal diverticulitis: CT findings. Diagn. Interv. Radiol. 13, 188-189.

Kouraklis, G., Mantas, D., Glivanou, A., Kouskos, E., Raftopoulos, J., Karatzas, G. (2001) Diverticular disease of the small bowel: report of 27 cases. Int. Surg. 86(4), 235-239.

Aiyegbeni B.; Jonnalagadda S.; Creedon L.; Teibe A. 
Krishnamurthy, S., Kelly, M. M., Rohrmann, C. A., Schuffler, M. D. (1983) Jejunal diverticulosis. A heterogenous disorder caused by a variety of abnormalities of smooth muscle or myenteric plexus. Gastroenterology 85(3), 538-547.

Kumar, D. (2017) Complicated jejunal diverticulitis with unusual presentation. Radiol. Case Rep. 13(1), 58-64.

Mantas, D., Kykalos, S., Kouraklis, G. (2011) Small intestine diverticula: Is there anything new? World J. Gastrointest. Surg. 3(4), 49-53.

McLean, A. M., Paul, J. R., Kritzman, J., Farthing, M. J. (1985) Malabsorption in Marfan (Ehlers-Danlos) syndrome. J. Clin. Gastroenterol. 7(4), 304-308.

Prough, H., Jaffe, S., Jones, B. (2019) Jejunal diverticulitis. J. Surg. Case Rep. 1, 1-3.

Shapira, O., Mavor, E., Simon, D., Rothstein, H., Pfeffermann, R. (1992) Multiple giant gastrointestinal diverticula complicated by perforated jejunoileal diverticulitis in Marfan syndrome. Dig. Surg. 9(1), 58-60.

Vallicelli, C., Coccolini, F., Catena, F., Ansaloni, L., Montori, G., Di Saverio, S., Pinna, A. D. (2011) Small bowel emergency surgery: literature's review. World J. Emerg. Surg. 6(1), 1.

Yağmur, Y., Aldemir, M., Büyükbayram, H., Taçyıldız, I. (2004) Multiple jejunal diverticulitis with perforation in a patient with systemic lupus erythematosus: report of a case. Surg. Today 34(2), 163-166. 